\title{
Inpatient management of Hirschsprung's associated enterocolitis treatment: the benefits of standardized care (Svetanoff WJ et al., Pediatr Surg Int (2020) 26:1413-1421)
}

\author{
José Estevão-Costa ${ }^{1}\left[\right.$ (]) Ana Catarina Fragoso ${ }^{1}$. José Luís Carvalho ${ }^{1}$ \\ Accepted: 6 January 2021 / Published online: 26 January 2021 \\ (c) The Author(s), under exclusive licence to Springer-Verlag GmbH, DE part of Springer Nature 2021
}

\section{Dear Sir,}

We read with interest the article concerning Hirschsprung's associated enterocolitis (HAEC) published by Svetanoff et al. [1]. In a series of 57 patients with a relatively high prevalence (48\%) and recurrence (30\%) of postoperative HAEC, the authors demonstrated that a standardized care improves some outcomes such as lower duration of IV antibiotics, lower duration of TPN, lower length of hospital stay, and more importantly a significant decrease of recurrence rate.

Risk factors for developing postoperative HAEC may, in fact, have a substantial impact on the algorithm treatment. Beyond the mentioned ones (trisomy 21, long-segment disease, obstruction and prior episodes), the histopathology of the retained proximal colon may have decisive impact on the occurrence of postoperative enterocolitis.

In the present article, there is mention of performing fullthickness rectal biopsies in patients with recurrent HAEC. Despite there is no description on pathological examination of these specimens, we agree with the objective, e.g., to rule out a transition zone or an aganglionic pull-through. However, we add another one: to rule out the presence of other dysganglionoses, mainly type B intestinal neuronal dysplasia (IND) that frequently coexist in the colon proximal to aganglionic segment. A relationship between postoperative HAEC and coexisting IND has been observed by some authors and ourselves [2-5]. Using appropriate histochemical examination, we perform colonic mapping prior to pull-through by a minimally invasive procedure; an extended proximal colonic resection has been carried out in case of coexisting IND, what has resulted in a minimal (as low as 5\%) prevalence of postoperative HAEC [3, 6]. The previous procedure may be avoided if a rapid histochemical method

José Estevão-Costa

estevao@med.up.pt

1 Department of Pediatric Surgery, Faculty of Medicine, Hospital S. João, 4200-319 Porto, Portugal and/or an experienced pathologist is available for the examination of frozen specimens at time of pull-through.

A standardized algorithm such as this of Svetanoff et al. [1] is desirable because outcomes must be more robust; nevertheless, a significant distribution of coexisting IND might be present in the two periods, what may alter the repercussion of a comparison between them. To know the results of examination of full-thickness rectal biopsies in patients with recurrent HAEC, if available, may be relevant for pediatric surgeons who deal with Hirschsprung's disease.

\section{References}

1. Svetanoff WJ, Dekonenko C, Osuchukwu O et al (2020) Inpatient management of Hirschsprung's associated enterocolitis treatment: the benefits of standardized care. Pediatr Surg Int 36:1413-1421

2. Estevão-Costa J, Carvalho JL, Soares-Oliveira M (2000) Enterocolitis risk factors after pull-through for Hirschsprung's disease. J Pediatr Surg 35:153

3. Estevão-Costa J, Fragoso AC, Campos M, Soares-Oliveira M, Carvalho JL (2006) An approach to minimize postoperative enterocolitis in Hirschsprung's disease. J Pediatr Surg 41:1704-1707

4. Kobayashi H, Hirakawa H, Pruri P et al (1995) Intestinal neuronal dysplasia is a possible cause of persistent bowel symptoms after pull-through operation for Hirschsprung's disease. J Pediatr Surg 30:253-259

5. Ure BM, Holschneider AM, Schulten D et al (1997) Clinical impact of intestinal neuronal malformations: a prospective study in 141 patients. Pediatr Surg Int 12:377-382

6. Carvalho JL, Campos M, Soares-Oliveira M, Estevão-Costa J (2001) Laparoscopic colonic mapping of dysganglionosis. Pediatr Surg Int 17:493-495

Publisher's Note Springer Nature remains neutral with regard to jurisdictional claims in published maps and institutional affiliations. 